https://doi.org/10.15407/ujpe64.9.803

A.O. MALININA, A.K. SHUAIBOV, O.M. MALININ

Uzhgorod National University

(64,Voloshyna Str.,Uzhgorod 88000,Ukraine; e-mail: antonina.malinina@uzhnu.edu.ua)

\title{
MECHANISM ENHANCING THE EMISSION POWER OF GAS-DISCHARGE LAMPS BASED ON MIXTURES OF NEON, NITROGEN, AND MERCURY DICHLORIDE VAPOR IN THE BLUE-GREEN SPECTRAL INTERVAL
}

\begin{abstract}
A mechanism enhancing the radiation power of a gas-discharge lamp based on a mixture of neon, nitrogen, and a mercury dichloride vapor in the blue-green spectral interval as compared with that for a lamp based on a mixture of only neon and a mercury dichloride vapor has been determined. The optical characteristics and the plasma parameters, as well as the value of the reduced electric field, at which the specific discharge power introduced into the excitation of exciplex molecules of mercury monochloride is maximum, are found. The research results can be used to create a more efficient exciplex lamp that emits radiation bands in the blue-green spectral interval.

Keywords: discharge lamp, barrier discharge, radiation emission by exciplex molecules, plasma parameters, mercury dichloride, nitrogen, neon.
\end{abstract}

\section{Introduction}

Discharge plasma that arises in the mixture of a mercury dichloride vapor with other gases is a working medium for exciplex sources of coherent and spontaneous radiation in the blue-green spectral interval with the wavelength $\lambda=557 \mathrm{~nm}$ at the maximum emission intensity [1-12]. Such sources can be used in scientific researches, photonics, biotechnology, medicine, for the manufacture of gas-discharge indicator panels, as well as for the effective light control over photosynthesis, plant growth and development, and phytocenosis [13-17]. In contrast to available fluorescent lamps and thermal sources, exciplex lamps possess a number of advantages: (i) up to $90 \%$ or more of the total radiation power can be concentrated in a relatively narrow ( $\leq 10 \mathrm{~nm}$ at the half height) spectral band of a mercury monochloride molecule, and (ii) the specific radiation power exceeds the values

(C) A.O. MALININA, A.K. SHUAIBOV,

O.M. MALININ, 2019

ISSN 2071-0194. Ukr. J. Phys. 2019. Vol. 64, No. 9 that are characteristic of low-pressure lamps based on the resonance transitions in metal atoms [18-20]. During the last decade, LED lamps, which have the highest light yield (about $100 \mathrm{~lm} / \mathrm{W}$ ) in comparison with other light sources, became widely applied in the blue-green spectral interval. However, the application of powerful (more than $100 \mathrm{~W}$ ) LED lamps is rather limited, because they have to be cooled down for their operational ability not to be lost [21]. There is no such limitation for excilamps in the visible spectral range, because the working surface of a radiator bulb can be scaled without changing the specific energy parameters $[18,19]$.

The creation of a gas-discharge plasma and the excitation of components in the working mixture of exciplex radiation sources were performed in the bulk, glowing, barrier, and surface discharges. In the sources of spontaneous radiation, helium was mainly used as a buffer gas. The lamps had a coaxial design, and the lateral surface of a quartz discharge tube served as the emitting area. For some scientific and 


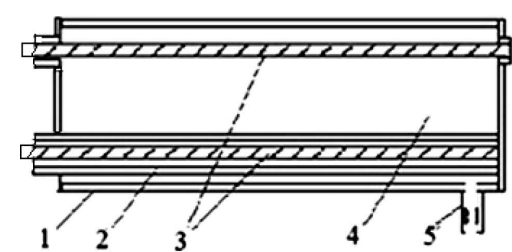

Fig. 1. Radiator design: outer quartz tube (1), inner quartz tube (2), electrodes (3), working chamber (4), appendix for pumping nitrogen in and out (5)

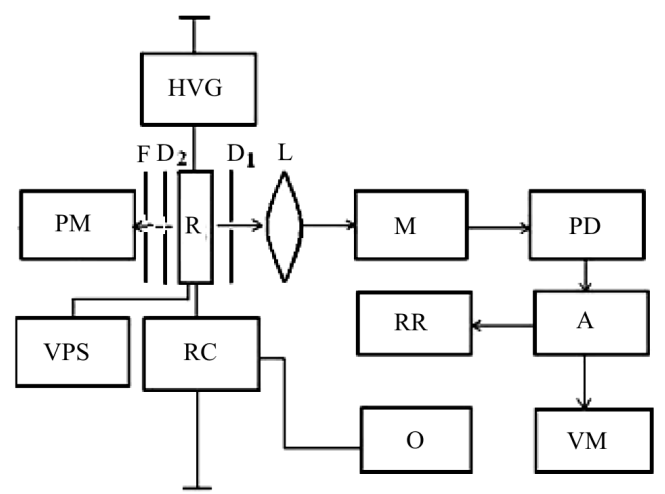

Fig. 2. Schematic diagram of experimental installation: radiator (R), high-voltage generator of periodic pulses (HVG), monochromator (M), photodetector (PD), amplifier (A), recorder (RR), voltmeter (VM), oscilloscope (O), Rogowski coil $(\mathrm{RC})$, vacuum pumping system (VPS), power meter (PM), lens $(\mathrm{L})$, diaphragms $\left(\mathrm{D}_{1}, \mathrm{D}_{2}\right)$, filter $(\mathrm{F})$

technological applications, it is necessary to provide a higher radiation density and its uniformity over the radiator cross-section. It is also required that buffer gases that are "heavier" than helium should be used in the working mixture, because they have a lower penetrating power through the radiator walls and, thus, provide a longer exploitation period of radiation sources $[15,18,19]$.

The latter requirement became the aim of our research. More specifically, the study included the experimental detection of regularities in the optical characteristics of a gas-discharge plasma based on the mixtures of a mercury dichloride vapor with neon and with a small admixture of nitrogen, and the determination of the partial pressures of neon and nitrogen, at which the power of radiation emitted by a radiator in the blue-green spectral interval is maximum. The numerical simulation of the examined plasma included the calculation of such plasma parameters as the energy distribution functions of electrons, the transport and energy characteristics of the latter, the specific power losses of an electric discharge in various elementary processes, the electron concentration and temperature, and the rate constants for the processes of elastic and inelastic electron scatterings by the working mixture components as functions of the reduced electric field $E / N$ (the ratio between the electric field strength and the total concentration of components in the working mixture). The calculation results made it possible to determine the optimum value of the $E / N$ parameter, at which the power of radiation emitted by the lamp is maximum. On the basis of experimentally found emission characteristics of the discharge and the calculated plasma parameters, the population mechanism was determined for the $B^{2} \Sigma_{1 / 2}^{+}$state of mercury monochloride molecules under the operational conditions for a discharge lamp based on the mixture of a mercury dichloride vapor, neon, and a low nitrogen admixture and with barrierdischarge pumping.

\section{Experimental Installation and Technique}

A gas-discharge plasma was formed in the mixtures of a mercury dichloride vapor and nitrogen with the help of the barrier discharge in a device shown in Fig. 1. The device was made from quartz tube 1 (34 $\mathrm{mm}$ in diameter, $200 \mathrm{~mm}$ in length). Two tungsten electrodes $3(5 \mathrm{~mm}$ in diameter) were arranged along the discharge tube axis at a distance of $15 \mathrm{~mm}$ from it. One of the electrodes was inserted into quartz tube 2 (9 $\mathrm{mm}$ in diameter). To reduce the escape of a mercury dichloride vapor from the lamp into the pumping and gas-filling system, quartz appendix 5 with a capillary $0.5 \mathrm{~mm}$ in diameter was welded to the lamp bulb.

The spectral, time, and energy characteristics of the discharge lamp emission were studied on an experimental installation, whose schematic diagram is shown in Fig. 2. The main units of this installation were as follows: radiator $(\mathrm{R})$, pumping and gas-filling system (PGFS), pulse voltage generator $(\mathrm{PVG})$, and radiation registration system. The latter included a monochromator SD-7 (M), photodetector (PD), photoelectron multiplier FEP-106 or linear electron multiplier 14ELU-FS, amplifier of electrical signals U5-9 (A), recorder KSP-4 (RR), voltmeter Shch-4300 (VM), oscilloscope S1-72 (O), and Rogowski coil (RC).

The working mixture was excited in the barrier discharge at the atmospheric pressure with the help of a 
power source providing a pulse-periodic output voltage. The pulse repetition frequency could be varied within an interval of $1-20 \mathrm{kHz}$, and the pulse voltage amplitude within an interval of $10-30 \mathrm{kV}$.

Working mixtures were prepared immediately in the device chamber. A powder of mercury dichloride salt $\left(\mathrm{HgCl}_{2}\right) 60 \mathrm{mg}$ in mass was uniformly poured into a gas-discharge cuvette. When studying the optical characteristics of radiation emission by a gasdischarge plasma, the partial pressure of a saturated mercury dichloride vapor was created with the help of the self-heating of the working gas-vapor mixture obtained as a result of the discharge energy dissipation. After the salt loading, the radiator was dehydrated by the heating at a temperature of $50{ }^{\circ} \mathrm{C}$ and the evacuation for two hours. The partial pressure of a saturated mercury dichloride vapor was determined according to the temperature of the coldest point of a radiator by interpolating the reference data of work [22]. The partial pressure of nitrogen was measured with the help of a standard diaphragm pressure gauge.

The discharge radiation was registered in the direction perpendicular to the lateral surface of a radiator quartz bulb and analyzed in a spectral interval of $420-600 \mathrm{~nm}$. The radiation spectrum was registered using a diffraction monochromator with a 600 -line $/ \mathrm{mm}$ grating. The spectral resolution of the registration system was $2.4 \mathrm{~nm}$. The registration system was calibrated with the help of a standard tungsten lamp SI 8-200 at the filament temperature $T=2173 \mathrm{~K}$.

The voltage and current pulses produced by the radiator were registered using an oscilloscope S1-72. A signal was supplied to the oscilloscope input from a voltage divider and the integrating circuit of a calibrated Rogowski coil.

The amplitude-versus-time characteristics of radiation were determined using a linear photomultiplier 14ELU-FS. Its signal was registered using an oscilloscope S1-72.

The average power of radiation emission by the lamp was measured using a Quartz-01 device. After passing through a $0.25-\mathrm{cm}^{2}$ diaphragm, the optical signal arrived at the measuring head of the device. The power $P_{\text {rad }}$ emitted from the whole radiator surface was determined using the expression [23]

$P_{\mathrm{rad}}=\Omega_{0} P_{\mathrm{reg}} / \Omega_{\mathrm{det}}$,

ISSN 2071-0194. Ukr. J. Phys. 2019. Vol. 64, No. 9 where $P_{\text {reg }}$ is the power registered by a photodetector, $\Omega_{0}$ the equivalent solid angle (its value equals $\pi^{2}$ for a cylindrical surface [16]), $\Omega_{\mathrm{det}}=S_{\mathrm{det}} / l_{0}^{2}$ is the solid angle of a photodetector, $S_{\text {det }}$ the area of a photodetector window, and $l_{0}$ the distance between a photodetector and the radiation source.

The pulse power $P_{\text {pulse }}$ was determined from the formula

$P_{\mathrm{av}}=P_{\text {pulse }} \Delta \tau f$

using the known average power $P_{\text {av }}$, as well as the duration $\Delta \tau$ and the repetition frequency $f$ of pulses.

\section{Research Results and Their Discussion}

Plasma radiation spectra were examined in the following partial pressure intervals: $0.5-2 \mathrm{kPa}$ for a mercury dichloride vapor, 5-140 kPs for neon, and 1$60 \mathrm{kPa}$ for nitrogen. The voltage, current, and pulse repetition frequency were equal to $20-30 \mathrm{kV}, 300$ $325 \mathrm{~A}$, and $10-20 \mathrm{kHz}$, respectively.

A characteristic radiation spectrum registered at the pulse repetition frequency $f=18 \mathrm{kHz}$ is shown in Fig. 3. The spectrum demonstrates only a system of electron-vibrational bands corresponding to the transition $B^{2} \Sigma_{1 / 2}^{+} \rightarrow X^{2} \Sigma_{1 / 2}^{+}, v^{\prime}=0 \div 5, v^{\prime \prime}=9 \div 19$ of a mercury chloride molecule $\left(\mathrm{HgCl}^{*}\right)$ [24] with a maximum radiation intensity at the wavelength $\lambda=$ $=557 \mathrm{~nm}$. The spectrum is characterized by a significant increase of the intensity on the long-wavelength side and a slow decrease of the radiation intensity in the short-wavelength region.

The shape of the spectral band and its halfheight width $(15-16 \mathrm{~nm})$ are similar to the parameters of spectral bands corresponding to the

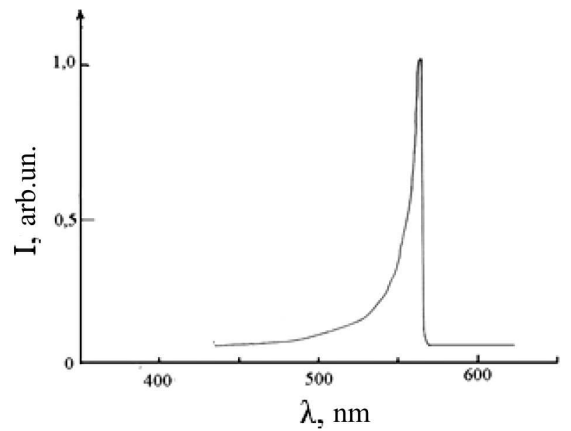

Fig. 3. Radiation spectrum of pulsed discharge in the $\mathrm{HgCl}_{2}$ $\mathrm{N}_{2}-\mathrm{Ne}(1.5-20-140 \mathrm{kPa})$ mixture. The pulse repetition frequency is $18 \mathrm{kHz}$ 


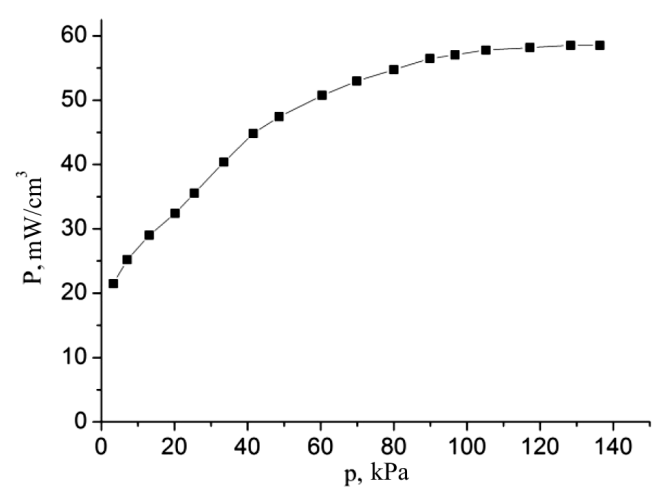

Fig. 4. Dependence of the radiation power emitted by a $\mathrm{HgCl}^{*}$ molecule in the $\lambda_{\max }=557-\mathrm{nm}$ spectral band on the partial pressure of neon for the discharge in the $\mathrm{HgCl}_{2}-\mathrm{Ne}$ mixture. The partial pressure of a $\mathrm{HgCl}_{2}$ vapor is $1.5 \mathrm{kPa}$, the voltage pulse amplitude is $30 \mathrm{kV}$, and the pulse repetition frequency is $18 \mathrm{kHz}$

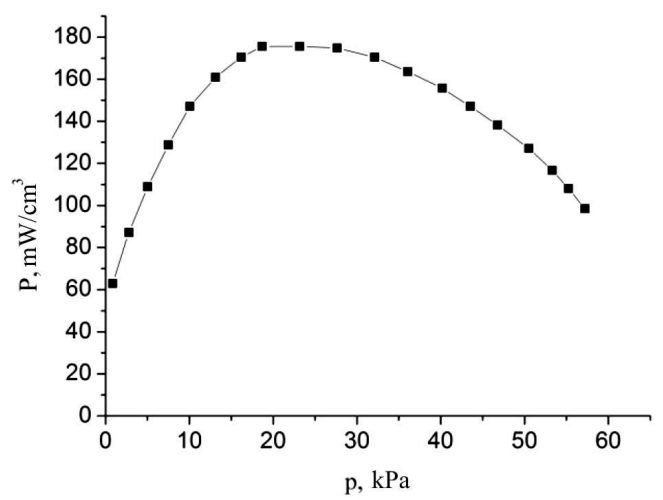

Fig. 5. Dependence of the radiation power emitted by a $\mathrm{HgCl}^{*}$ molecule in the $\lambda_{\max }=557-\mathrm{nm}$ spectral band on the partial pressure of nitrogen for the discharge in the $\mathrm{HgCl}_{2}-\mathrm{N}_{2}-\mathrm{Ne}$ mixture. The partial pressure of a $\mathrm{HgCl}_{2}$ vapor is $1.5 \mathrm{kPa}$, the partial pressure of neon is $140 \mathrm{kPs}$, the voltage pulse amplitude is $30 \mathrm{kV}$, and the pulse repetition frequency is $18 \mathrm{kHz}$

transition $B^{2} \Sigma_{1 / 2}^{+} \rightarrow X^{2} \Sigma_{1 / 2}^{+}$in mercury monohalogenides. Those spectra were obtained in the works, where the barrier discharge in the mixtures of a gas and a mercury dihalogenide vapor was formed in both large and small radiators. A drastic increase in the radiation spectrum intensity was observed in the longwavelength section and a slow decrease in the shortwavelength one. The spectra were characterized by an intensity decrease rate in the ultraviolet spectral section and by a broad radiation band. The radiation spectrum at low partial neon pressures $(<40 \mathrm{kPa})$, if compared with the partial pressures higher than the

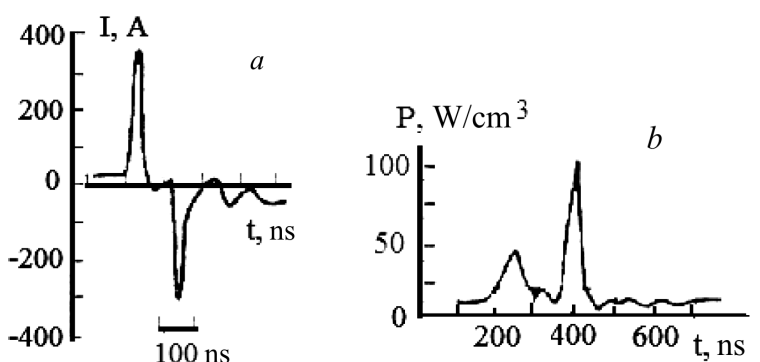

Fig. 6. Oscillograms of discharge current pulses $(a)$ and pulses of radiation power density $(b)$ for the $\lambda_{\max }=557-\mathrm{nm}$ spectral band of a $\mathrm{HgCl}^{*}$ molecule in the discharge in the $\mathrm{HgCl}_{2}-\mathrm{N}_{2}-$ $\mathrm{Ne}$ mixture. The partial pressure of a $\mathrm{HgCl}_{2}$ vapor is $1.5 \mathrm{kPa}$, the partial pressure of nitrogen is $20 \mathrm{kPs}$, the partial pressure of neon is $140 \mathrm{kPs}$, the voltage pulse amplitude is $30 \mathrm{kV}$, and the pulse repetition frequency is $18 \mathrm{kHz}$

atmospheric one, was wider and extended further into the ultraviolet region.

The research results obtained for the integral characteristics, i.e., the dependence of the average radiation power on the partial pressures of the buffer neon and nitrogen gases, are shown in Figs. 4 and 5, respectively. For the discharge in the mixture of neon and a mercury dichloride vapor, an increase of the radiation power from 28 to $60 \mathrm{~mW} / \mathrm{cm}^{3}$ was observed with the growth of the neon partial pressure. At the same time, for a plasma in the gas mixture with the addition of nitrogen, the radiation power firstly increased to $180 \mathrm{~mW} / \mathrm{cm}^{3}$, when the nitrogen partial pressure increased from 0 to $20 \mathrm{kPa}$; then it reached a plateau; finally, if the partial pressure of nitrogen grew further, a drastic decrease of the radiation power was observed in a pressure interval of $30-60 \mathrm{kPa}$.

The research results obtained for the temporal characteristics of a discharge plasma are presented in Fig. 6. Figure 6, a illustrates an oscillogram of barrier discharge current pulses, and Fig. $6, b$ shows an oscillogram of the radiation power, for the mixture component content, at which the radiation power reached a maximum value. The maximum of the current pulse amplitude was $375 \mathrm{~A}$. The current pulses were double, with different polarities, and a delay between them was $150 \mathrm{~ns}$ under our experimental conditions. The leading edge of a pulse was $10 \mathrm{~ns}$ long, and the total pulse duration was $50 \mathrm{~ns}$. The emitted radiation pulses were also double, with the relative time shift between the components being equal to $150 \mathrm{~ns}$. The amplitudes of the components were different in magnitude: the amplitude of the second 
pulse was larger. The error and reproducibility of the results of oscilloscopic measurements were $10 \%$ and $90 \%$, respectively.

With the growth of the pulse repetition frequency, the average emission power of a gas-discharge plasma increased linearly up to $20 \mathrm{kHz}$. The discharge behavior was similar to that described in work [25]. It was observed visually that, as the pump pulse repetition frequency increased, the radiation emission intensity by a homogeneous discharge increased, whereas the radiation intensity of filamentary channels decreased. The thickness of the discharge region and the length of the discharge burning section amounted to 0.005 and $0.20 \mathrm{~m}$, respectively.

\section{Plasma Parameters}

Nowadays, experimental physics does not possess satisfactory methods for the diagnostics of a dense gasdischarge plasma. Therefore, the parameters of a barrier discharge plasma under the optimal conditions for obtaining the maximum radiation power of the electric discharge in the $\mathrm{HgCl}_{2}-\mathrm{Ne}(0.0107-0.9893)$ mixture at a total pressure of $141.5 \mathrm{kPa}$ and the $\mathrm{HgCl}_{2}-\mathrm{N}_{2}-\mathrm{Ne}(0.0093-0.1238-0.8669)$ mixture at a total pressure of $161.5 \mathrm{kPa}$ were determined numerically. They were calculated as complete integrals of the electron distribution function over the energy (EDFE). The latter was determined, by solving the Boltzmann equation in the two-term approximation [26]. The EDFE calculations were performed using the well-known Bolsig + computer program [27].

The calculated EDFEs were used to find the average energy of electrons and the specific losses of the electric discharge power for various elementary processes in a plasma, as well as the rate constants for the elastic and non-elastic electron scatterings by mercury dichloride and nitrogen molecules and neon atoms and their dependences on the reduced electric field magnitude $E / N$. In calculations, the variation interval of the parameter $E / N$ was equal to $1-150 \mathrm{Td}$, i.e. $1 \times 10^{-17}-15 \times 10^{-16} \mathrm{~V} \mathrm{~cm}^{2}$, and it included the values of this parameter that were realized in our experiments. All calculations were carried out for the discharge at the partial pressures of a mercury dichloride vapor and neon equal to 1.5 and $140 \mathrm{kPa}$, respectively, in the $\mathrm{HgCl}_{2}-\mathrm{Ne}$ mixture and at the partial pressures of a mercury dichloride vapor, neon, and nitrogen equal to $1.5,140$, and $20 \mathrm{kPa}$, respectively, in the $\mathrm{HgCl}_{2}-\mathrm{Ne}-\mathrm{N}_{2}$ mixture, at which the experimentally attained radiation power was maximum (Figs. 4 and 5 , respectively).

When solving the Boltzmann kinetic equation, the following processes were taken into account in the integral of electron collisions with mercury dichloride, nitrogen, and neon molecules:

- elastic scattering and excitation of the energy levels of a nitrogen molecule:

- rotational level (a threshold energy of $0.020 \mathrm{eV}$ );

- vibrational levels (threshold energies of 0.290, $0.291,0.590,0.880,1.170,1.470,1.760,2.060$, and $2.350 \mathrm{eV}$;

- electron states at 6.170, 7.000, 7.350, 7.360, 7.800, $8.160,8.400,8.550,8.890,11.03,11.87,12.25$, and $13.00 \mathrm{eV}$

- ionization (a threshold energy of $15.60 \mathrm{eV}$ );

- elastic scattering and excitation of energy levels of an Ne atom with threshold energies of $16.62,16.67$ $(1 s 4), 16.84(1 s 2), 18.72(2 p), 20.0(2 s+3 d), 20.65$ $(3 p)$, and $4.9 \mathrm{eV}$;

- ionization of a neon atom;

- dissociative excitation of electron states of mercury monochloride $\left(B^{2} \Sigma_{1 / 2}^{+}\right)$;

- ionization of mercury dichloride molecules.

The data concerning the absolute values for the effective cross-sections of those processes, as well as their dependences on the electron energy, were taken from database [27] and works [28, 29].

The electric field strength in a plasma, $E$, was calculated by the formula [30]

$E=U_{\mathrm{pl}} / d$

where $U_{\mathrm{pl}}$ is the voltage applied across a plasma, and $d$ is the discharge gap width. The voltage $U_{\mathrm{pl}}$ applied across a plasma was determined in accordance with the second Kirchhoff rule, i.e., making use of experimentally measured values for the time behavior of the voltage $U$ applied to electrodes 3 (Fig. 1) of radiator $\mathrm{R}$ with regard for the voltage drop $U_{\text {ins }}$ across the capacitance of insulator 2 (Fig. 1) [6,30],

$U_{\mathrm{pl}}=U-U_{\mathrm{ins}}$.

The voltage $U_{\text {ins }}$ was calculated from the displaced charge $Q$ and the dielectric barrier capacitance $C_{d}$,

$U_{\mathrm{ins}}=Q / C_{d}$ 


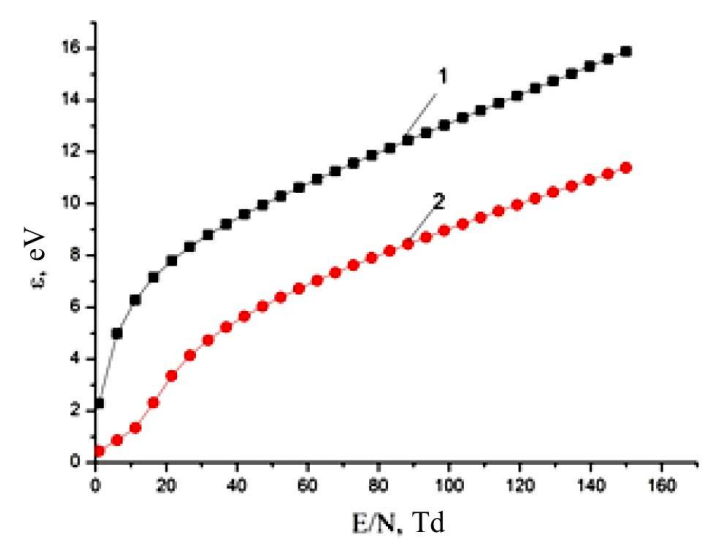

Fig. 7. Dependences of the average electron energy on the parameter $E / N$ for the discharge (1) in the $\mathrm{HgCl}_{2}-\mathrm{Ne}(0.0107$ 0.9893 ) mixture at a total pressure of $141.5 \mathrm{kPa}$ and (2) in the $\mathrm{HgCl}_{2}-\mathrm{N}_{2}-\mathrm{Ne}(0.0093-0.1238-0.8669)$ mixture at a total pressure of $161.5 \mathrm{kPa}$

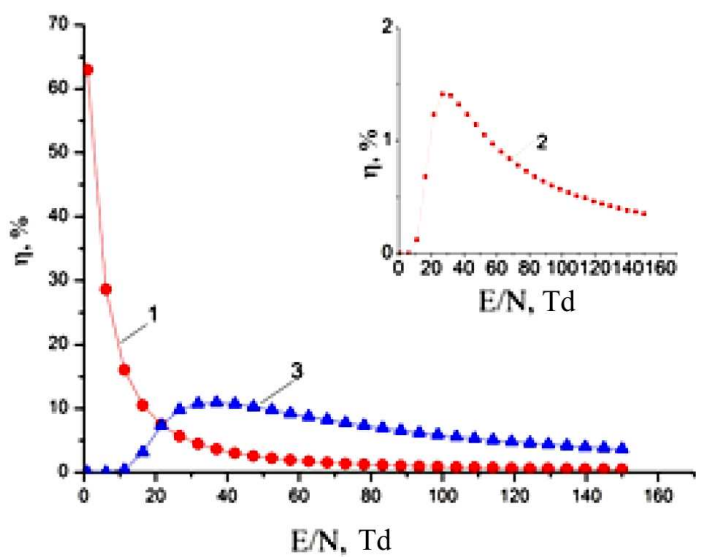

Fig. 8. Dependences of the specific discharge power losses spent on the dissociative electron excitation of the $B^{2} \Sigma_{1 / 2}^{+}$ state of a mercury monochloride molecule in the discharge (1) in the $\mathrm{HgCl}_{2}-\mathrm{Ne}(0.0107-0.9893)$ mixture at a total pressure of $141.5 \mathrm{kPa}$ and (2) in the $\mathrm{HgCl}_{2}-\mathrm{N}_{2}-\mathrm{Ne}(0.0093-0.1238-$ $0.8669)$ mixture at a total pressure of $161.5 \mathrm{kPa}$, and (3) spent on the excitation of the metastable $B^{3} \Pi_{g}$ state of nitrogen molecules on the parameter $E / N$

The charge displaced in the circuit was determined by integrating the current $I$ and taking the initial conditions into account,

$Q(t)=\int_{0}^{t} I(t) d t+Q_{0}$,

where $Q_{0}=Q(t=0)$.
In the case of a discharge in the mixture of a mercury dichloride vapor and neon, the electric field strength in a plasma was equal to $E=2.2 \times 10^{6} \mathrm{~V} / \mathrm{m}$ and the reduced electric field to $E / N=100 \mathrm{Td}$ for the total concentration of mixture components $N=2.2 \times 10^{25} \mathrm{~m}^{-3}$, at which the maximum emission power in the spectral band of a mercury monochloride molecule $\left(\lambda_{\max }=557 \mathrm{~nm}\right.$ ) was experimentally observed. The corresponding values of those parameters in the case of the mercury dichloride vapor + + neon + nitrogen mixture were as follows: $E=2.2 \times$ $\times 10^{6} \mathrm{~V} / \mathrm{m}, E / N=90 \mathrm{Td}$, and $N=2.5 \times 10^{25} \mathrm{~m}^{-3}$.

The dependence of the average energy of discharge electrons on the parameter $E / N$ in a plasma based on the $\mathrm{HgCl}_{2}-\mathrm{Ne}$ mixture is the strongest in the interval $E / N=1 \div 17 \mathrm{Td}$, where it increases linearly from 2.3 to $7.2 \mathrm{eV}$ (Fig. 6, curve 1). In the interval $E / N=17 \div 150 \mathrm{Td}$, the average electron energy also increases (from 7.2 to $15.9 \mathrm{eV}$ ), but more slowly. The average energy of electrons increases more slowly in this $E / N$-interval because of the energy losses by fast electrons on the excitation of energy states in a mercury dichloride molecule and a neon atom. For the discharge in the $\mathrm{HgCl}_{2}-\mathrm{N}_{2}-\mathrm{Ne}$ mixture, the dependence of the average energy of discharge electrons on the parameter $E / N$ is the strongest in the interval $E / N=1 \div 21.6 \mathrm{Td}$ (Fig. 7, curve 2), where it increases linearly from 0.4 to $3.4 \mathrm{eV}$. Again, in the interval $E / N=21.6 \div 150 \mathrm{Td}$, the average electron energy increases more slowly from 3.4 to $11.4 \mathrm{eV}$, which is associated with the energy losses by fast electrons on the excitation of energy states in a mercury dichloride molecule, nitrogen molecule, and neon atom. For the reduced electric fields of 100 and $90 \mathrm{Td}$, at which the experimental studies were carried out, the average electron energy was equal to 13.1 and $8.5 \mathrm{eV}$, the maximum electron energy to 121 and $80 \mathrm{eV}$, the electron drift velocity to $2.4 \times 10^{5}$ and $2.2 \times 10^{3} \mathrm{~m} / \mathrm{s}$, and the electron concentration to $0.98 \times 10^{6}$ and $1.07 \times 10^{6} \mathrm{~m}^{-3}$ for plasmas in the $\mathrm{HgCl}_{2}-\mathrm{Ne}$ and $\mathrm{HgCl}_{2}-\mathrm{N}_{2}-\mathrm{Ne}$ mixtures, respectively.

The distribution of the specific discharge power losses on main elementary processes, when the reduced electric field strength varies within the interval $E / N=1 \div 150 \mathrm{Td}$, is shown in Fig. 8. For the process of dissociative electron excitation of the $B^{2} \Sigma_{1 / 2}^{+}$ state of mercury monochloride molecules, the specific power losses of the discharge increase with the parameter $E / N$. They reach maximum values of $63 \%$ and 
$1.4 \%$ at $E / N=1$ and $26.7 \mathrm{Td}$ in the discharge in the $\mathrm{HgCl}_{2}-\mathrm{Ne}$ and $\mathrm{HgCl}_{2}-\mathrm{N}_{2}-\mathrm{Ne}$ mixtures, respectively, and decrease, if the $E / N$ parameter increases further. The specific power losses of a discharge on the excitation of the metastable $B^{3} \Pi_{g}$ state of a nitrogen molecule (Fig. 7, curve 3) has a similar dependence on the reduced electric field strength and reached a maximum of $11 \%$ at $E / N=37 \mathrm{Td}$.

The magnitudes of specific discharge power losses on those processes and the rates of their increase or decrease are associated with the absolute values of the effective cross-sections of the energy states and the character of their dependence on the electron energy, with the dependence of the EDFE on $E / N$, and with the threshold energies of dissociative excitation for mercury monochloride and nitrogen molecules and a neon atom. For the process of dissociative electron excitation of the $B^{2} \Sigma_{1 / 2}^{+}$state of a mercury monochloride molecule, the specific discharge power losses amounted to $0.9 \%$ and $0.6 \%$ at the experimental reduced electric field strengths $E / N=100$ and $90 \mathrm{Td}$ in a plasma in the $\mathrm{HgCl}_{2}-$ $\mathrm{Ne}$ and $\mathrm{HgCl}_{2}-\mathrm{N}_{2}-\mathrm{Ne}$ mixtures, respectively. For the electron excitation of the metastable $B^{3} \Pi_{g}$ state of a nitrogen molecule, the specific discharge power losses amounted to $6.2 \%$ for the reduced electric field strength $E / N=90 \mathrm{Td}$.

Figure 9 illustrates the results of numerical calculations for the rate constants of the dissociative electron excitation of the $B^{2} \Sigma_{1 / 2}^{+}$state of a mercury monochloride molecule (curves 1 and 2) and the electron excitation of the metastable $B^{3} \Pi_{g}$ state of a nitrogen molecule (curve 3). The rate constants for the former process fall within an interval from $3 \times 10^{-25}$ to $3.4 \times 10^{-15} \mathrm{~m}^{3} / \mathrm{s}$, if the parameter $E / N$ varies from 1 to $150 \mathrm{Td}$. For the reduced electric field strengths $E / N=100$ and $90 \mathrm{Td}$, the dissociative electron excitation rate constants for the $B^{2} \Sigma_{1 / 2}^{+}$state of a mercury monochloride molecule equal $3.1 \times 10^{-15} \mathrm{~m}^{3} / \mathrm{s}$ (fror the $\mathrm{HgCl}_{2}-\mathrm{Ne}$ mixture) and $2.1 \times 10^{-15} \mathrm{~m}^{3} / \mathrm{s}$ (for the $\mathrm{HgCl}_{2}-\mathrm{N}_{2}-\mathrm{Ne}$ mixture), respectively.

In the case of a gas-discharge plasma in the mixture of a mercury dichloride vapor with neon and nitrogen, the spectral bands with a maximum at the wavelength $\lambda=557 \mathrm{~nm}$, which corresponds to the electronvibrational transition $B^{2} \Sigma_{1 / 2}^{+} \rightarrow X^{2} \Sigma_{1 / 2}^{+}$of a $\mathrm{HgCl}^{*}$ molecule, arise as a result of the processes leading to the formation and destruction of the $B^{2} \Sigma_{1 / 2}^{+}$state of

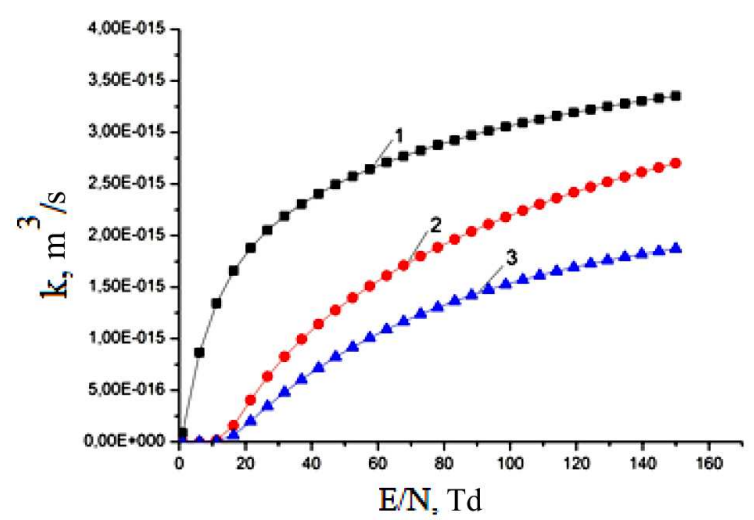

Fig. 9. Dependences of the rate constant of the dissociative electron excitation of the $B^{2} \Sigma_{1 / 2}^{+}$state of a mercury monochloride molecule in the discharge (1) in the $\mathrm{HgCl}_{2}-\mathrm{Ne}(0.0107-$ 0.9893 ) mixture at a total pressure of $141.5 \mathrm{kPa}$ and (2) in the $\mathrm{HgCl}_{2}-\mathrm{N}_{2}-\mathrm{Ne}(0.0093-0.1238-0.8669)$ mixture at a total pressure of $161.5 \mathrm{kPa}$, and (3) the rate constant of the dissociative electron excitation of the $B^{3} \Pi_{g}$ state of nitrogen molecules on the parameter $E / N$

mercury monochloride. The main of those processes are as follows [28, 29, 31, 32]:

$$
\begin{aligned}
& \mathrm{HgCl}_{2}+\mathrm{e} \rightarrow \mathrm{HgCl}_{2}\left({ }^{3,1} \Sigma_{u}^{+}\right) \rightarrow \\
& \mathrm{Cl}+\mathrm{e} \\
& \mathrm{Cl} \\
& \mathrm{HgCl}\left(B^{2} \Sigma_{1 / 2}^{+}\right)+ \\
& \operatorname{HgCl}\left(B^{2} \Sigma_{1 / 2}^{+}\right) \rightarrow \operatorname{HgCl}\left(X^{2} \Sigma_{1 / 2}^{+}\right)+h \nu, \\
& \lambda_{\max }=557 \mathrm{~nm}
\end{aligned}
$$

and

$\operatorname{HgCl}\left(B^{2} \Sigma_{1 / 2}^{+}\right)+M \rightarrow \operatorname{HgCl}\left(X^{2} \Sigma_{1 / 2}^{+}\right)+M+\Delta E$,

where $M$ is the concentration of $\mathrm{HgCl}_{2}$ and $\mathrm{N}_{2}$ molecules and $\mathrm{Ne}$ atoms, and $\Delta E$ is the reaction energy difference. Reactions (1) are the main source of the formation of exciplex $\mathrm{HgCl}^{*}$ molecules [28, 29]. The electron-vibrational transitions $B^{2} \Sigma_{1 / 2}^{+} \rightarrow$ $\rightarrow X^{2} \Sigma_{1 / 2}^{+}$in $\mathrm{HgCl}^{*}$ molecules lead to the emission of spectral bands with the maximum intensity at the wavelength $\lambda_{\max }=557 \mathrm{~nm}$ (reaction (2)). In the quenching reaction (3), the electron-vibrational transition of a mercury dichloride molecule into the ground state takes place without radiation emission.

In addition to processes (1)-(3) resulting in the formation or destruction of the $B^{2} \Sigma_{1 / 2}^{+}$state of a mercury monochloride molecule, the following processes 
are also possible:

$$
\begin{aligned}
& \mathrm{HgCl}_{2}+\mathrm{e} \rightarrow \mathrm{HgCl}_{2}(D) \rightarrow \\
& \rightarrow \mathrm{HgCl}\left(C^{2} \Pi_{1 / 2}, D^{2} \Pi_{3 / 2}\right)+\mathrm{Cl}+\mathrm{e},
\end{aligned}
$$

and

$$
\begin{aligned}
& \operatorname{HgCl}\left(C^{2} \Pi_{1 / 2}, D^{2} \Pi_{3 / 2}\right)+\mathrm{HgCl}_{2}\left(\mathrm{~N}_{2}, \mathrm{Ne}\right) \rightarrow \\
& \rightarrow \operatorname{HgCl}\left(B^{2} \Sigma_{1 / 2}^{+}\right)+M+\Delta E_{1.2} .
\end{aligned}
$$

Process (4) describes the electron excitation of $\mathrm{HgCl}_{2}$ molecules into the state $D[33,34]$. This state of a mercury dichloride molecule is the sum of all states located between the threshold energy $(6.4 \mathrm{eV})$ and the ionization energy $(11.4 \mathrm{eV})[33]$. One may expect that the effective electron excitation cross-section for this state of a mercury dichloride molecule should be close to the corresponding parameter for the $D$ state of a mercury dibromide molecule, which equals $10^{-5} \mathrm{~cm}^{2}$ [34]. No emission by a $\mathrm{HgCl}_{2}$ molecule in the $D$ state is observed, because this state redissociates with the formation of a mercury monochloride molecule in the $C$ or $D$ state. Under our experimental conditions, the emission from the $C$ and $D$ states of a mercury monochloride molecule was not observed owing to the high efficiency of the quenching process (5) [6]. The population of this state is transmitted into the $B^{2} \Sigma_{1 / 2}^{+}$state of $\mathrm{HgCl}$ molecules or into other non-optical channels [6,34].

A drastic intensity increase in the long-wavelength region of the spectrum and a slow decrease in its short-wavelength region (Fig. 3) can be explained by the behavior of potential curves (the excited $B^{2} \Sigma_{1 / 2}^{+}$state turns out shifted with respect to the $X^{2} \Sigma_{1 / 2}^{+}$state toward larger distances between the nuclei) and the relaxation processes in the populations of the upper oscillatory levels of the excited electron state (those processes take a shorter time, than the electron-oscillatory transition into the ground $X^{2} \Sigma_{1 / 2}^{+}$state does $\left.[35,36]\right)$.

The behavior of the dependence of the radiation emission power by $\mathrm{HgCl}^{*}$ molecules on the partial pressure of neon and nitrogen (Figs. 4 and 5, respectively) is governed, first of all, by the following processes:

- the electron concentration growth with an increase of the partial pressure of neon or nitrogen in the mixture,
- the change of the discharge energy fraction that is spent to heat up the working mixture,

- the variations of the average electron energy and the rate constant for the excitation of a mercury monochloride molecule with the change of the parameter $E / N$, and

- the quenching of the $B^{2} \Sigma_{1 / 2}^{+}$state of a $\mathrm{HgCl}^{*}$ molecule, when the latter collides with neon atoms and nitrogen molecules [30,37].

When the partial pressure of neon or nitrogen in the mixture decreases, the value of the parameter $E / N$ decreases. As a result, the fraction of the discharge power that is spent on the elastic scattering of electrons by neon atoms or nitrogen or mercury dichloride molecules increases, and, accordingly, the partial pressure of a mercury dichloride vapor and the radiation power in the spectral band of $\mathrm{HgCl}^{*}$ molecules grow. In addition, the increase of the radiation power with partial pressure of neon and nitrogen also favors the electron concentration growth, which increases together with the component concentrations in the working mixture [30]. The saturation of the radiation power magnitude, when the neon partial pressure continues to grow, is a result of the equilibrium established between the processes of excitation and quenching of the $B^{2} \Sigma_{1 / 2}^{+}$state of mercury monochloride molecules (processes (1)-(3)). A maximum and a further decrease of the radiation power emitted by exciplex $\mathrm{HgCl}^{*}$ molecules, when the partial pressure of nitrogen grows further, are induced by the quenching of the $B^{2} \Sigma_{1 / 2}^{+}$state of mercury monochloride molecules, when they collide with nitrogen molecules (process (3)) [30, 37]. The rate constants of this process for quenching the mercury monochloride molecules with neon atoms and nitrogen molecules equal $3.3 \times 10^{-20}$ and $6.1 \times 10^{-20} \mathrm{~m}^{3} / \mathrm{s}$, respectively [31].

The oscillatory structure of a current pulse (Fig. 6, a) is a result of the insulator capacitance charging and discharging during the voltage pulse action with an amplitude sufficient to break down the discharge gap [25]. The difference between the forms of current pulses at the front and back edges is explained by the opposite directions of a current flow through the discharge gap $\left(1.4 \times 10^{-2} \mathrm{~m}\right)$ and, as a result, different conditions of charge spreading over the inner surface of an insulator under conditions of onebarrier discharge, which was used in our experiment. 
The regularity in the difference between the intensity amplitudes of the first and second radiation pulses (Fig. 6, $b$ ) can be understood from the following consideration. The first and second pulses of the pump current give rise to the formation of a mercury monochloride molecule in the $B^{2} \Sigma_{1 / 2}^{+}$and $X^{2} \Sigma_{1 / 2}^{+}$ states owing to the dissociation of a mercury dichloride molecule at its collision with electrons. The second pump pulse brings about an additional increase in the population of the $B^{2} \Sigma_{1 / 2}^{+}$state of a mercury monochloride molecule according to the process

$e^{-}+\operatorname{HgCl}\left(X^{2} \Sigma_{1 / 2}^{+}\right) \rightarrow e^{-}+\operatorname{HgCl}\left(B^{2} \Sigma_{1 / 2}^{+}\right)$,

where $\operatorname{HgCl}\left(X^{2} \Sigma_{1 / 2}^{+}\right)$is a mercury monochloride molecule in the ground state, which had no time to recover into a triatomic molecule (mercury dichloride) in the reaction $[38,39]$

$\operatorname{HgCl}\left(X^{2} \Sigma_{1 / 2}^{+}\right)+\mathrm{Cl}+M \rightarrow \mathrm{HgCl}_{2}+\mathrm{N}_{2}$

within a 150-ns time interval between the pulses.

As follows from the calculation results (Figs. 7 9 ), the corresponding plasma parameters calculated for different gas mixture compositions $\left(\mathrm{HgCl}_{2}-\mathrm{Ne}\right.$ or $\mathrm{HgCl}_{2}-\mathrm{N}_{2}-\mathrm{Ne}$ ) at the experimental reduced electric field strengths of 100 and $90 \mathrm{Td}$, respectively, differ little from one another. Therefore, it is necessary to involve other elementary processes, which could explain a significant increase in the radiation power of a $\mathrm{HgCl}$ molecule $(B \rightarrow X)$ in the radiator based on the mixture of a mercury dichloride vapor with nitrogen and neon in comparison with the mixture without nitrogen (cf. Figs. 4 and 5). Such processes may include the process of energy transfer to mercury dichloride molecules at their collisions with nitrogen molecules in the metastable $B^{3} \Pi_{g}$ state $\left(E_{\mathrm{th}}=7.35 \mathrm{eV}\right)$,

$$
\begin{aligned}
& \mathrm{HgCl}_{2}+\mathrm{N}_{2}\left({ }^{3} \Pi_{g}\right) \rightarrow \mathrm{HgCl}_{2}(D) \rightarrow \\
& \rightarrow \mathrm{HgCl}\left({ }^{2} \Pi_{1 / 2}, D^{2} \Pi_{3 / 2}\right)+\mathrm{Cl}+\mathrm{e},
\end{aligned}
$$

as well as process (6) describing the quenching of the $C^{2} \Pi_{1 / 2}$ and $D^{2} \Pi_{3 / 2}$ states of a mercury monochloride molecule by mercury dichloride molecules, nitrogen molecules, and neon atoms with the radiationless transition into the $B^{2} \Sigma_{1 / 2}^{+}$state. According to the results of numerical calculations for the specific discharge power losses spent on the excitation of the metastable $B^{3} \Pi_{g}$ state of nitrogen molecules and their dependence on the parameter $E / N$ (Fig. 8, curve 3$)$, the population of the metastable $B^{3} \Pi_{g}$ state of a nitrogen molecule is maximum at the reduced electric field strength $E / N=37 \mathrm{Td}$. Accordingly, the population of the $B^{2} \Sigma_{1 / 2}^{+}$state of mercury monochloride molecules is also maximum at this $E / N$ value. This circumstance provides the maximum energy radiation characteristics in the band belonging to the blue-green spectral interval at a wavelength of $557 \mathrm{~nm}$ at the band intensity maximum.

\section{Conclusions}

To summarize, a comparison of the calculation results obtained for the parameters of a gas-discharge plasma in the $\mathrm{HgCl}_{2}-\mathrm{Ne}$ and $\mathrm{HgCl}_{2}-\mathrm{N}_{2}-\mathrm{Ne}$ gas mixtures with the experimental data made it possible to establish the mechanism responsible for the growth in the intensity of the $\mathrm{HgCl}(B \rightarrow X)$ emission in a gas-discharge plasma at the barrier discharge. This mechanism consists in that the population of the $B^{2} \Sigma_{1 / 2}^{+}$state of a mercury monochloride molecule increases owing to the collisions of nitrogen molecules in the metastable $B^{3} \Pi_{g}$ state with mercury dichloride molecules; then the mercury monochloride molecule redissociates into the $C^{2} \Pi_{1 / 2}$ and $D^{2} \Pi_{3 / 2}$ states of a mercury monochloride molecule; finally, the radiationless transitions from those states at their quenching by mercury dichloride and into the $B^{2} \Sigma_{1 / 2}^{+}$state of mercury monochloride and nitrogen molecules, as well neon atoms, take place.

Our researches allowed the value of the reduced electric field strength to be determined, at which the specific contribution of the discharge electric power to the excitation of the $B^{2} \Sigma_{1 / 2}^{+}$state of mercury monochloride molecules in the discharge in the $\mathrm{HgCl}_{2}-\mathrm{N}_{2}-\mathrm{Ne}$ mixture is maximum, namely, $E / N=$ $37 \mathrm{Td}$, which makes it possible to enhance the energy parameters of exciplex lamps emitting in the bluegreen spectral interval.

1. J.H. Parks. Laser action on the $B^{2} \Sigma_{1 / 2}^{+} \rightarrow X^{2} \Sigma_{1 / 2}^{+}$band of $\mathrm{HgBr}$ at 5018 Å. Appl. Phys. Lett. 31, 297 (1977).

2. R. Burnliam. Discharge pumped mercuric halide dissociation lasers. Appl. Phys. Lett. 33, 152 (1978).

3. I.S. Lakoba, S.I. Yakovlenko. Active media of exciplex lasers (A review). Kvant. Elektron. 7, 677 (1980) (in Russian).

4. R. Burnham, E.J. Schimitschek. High-power blue-green lasers. Laser Focus 6, 54 (1981). 
5. S.P. Bazhulin, N.G. Basov, S.N. Bugrimov, V.S. Zuev, A.S. Kamrukov, G.N. Kashnikov, N.P. Kozlov, P.A. Ovchinnikov, A.G. Opekan, V.K. Orlov, Yu.S. Protasov. Green-emitting mercury chloride laser pumped by wideband optical radiation. Sov. J. Quant. Electron. 16, 836 (1986).

6. A.M. Boichenko, M.I. Lomaev, A.N. Panchenko et al. Ultraviolet and Vacuum-Ultraviolet Excilamps: Physics, Technology and Applications (STT, 2011) (in Russian).

7. A.N. Malinin. Excitation of mercury monohalides in the plasma of pulse-periodic discharge in mixtures of mercury dihalides and rare gases. Laser Phys. 7, 1032 (1997).

8. A.N. Malinin. The main characteristics of the plasma of pulse glow discharge in mixtures of mercury dihalides and rare gases. Laser Phys. 8, 395 (1998).

9. M.M. Guivan, O.M. Malinin, L.L. Shimon. Optimization of the component composition of gas-discharge $\mathrm{HgBr}$-excimer lamps. Nauk. Visn. Uzhgorod. Univ. 4, 12 (1999) (in Ukrainian).

10. A.N. Malinin, N.N. Guivan, L.L. Shimon. Emission spectra of working mixtures of the $\mathrm{HgBr} / \mathrm{HgCl}$ excimer lamp. Opt. Spektrosk. 89, 905 (2000) (in Russian).

11. M.M. Guivan, O.M. Malinin, L.L. Shimon. Optimization of optical characteristics of working mixtures for $\mathrm{HgBr}$ and $\mathrm{HgCl}$ exilamps. Zh. Fiz. Dosl. 6, 74 (2002) (in Ukrainian).

12. M.M. Guivan, A.N. Malinin. Investigation of the process of excitation of mercury monobromide and monochloride excimer molecules in dense gas-discharge plasma. Ukr. J. Phys. 47, 24 (2002).

13. Yu.I. Posudin. Laser Photobiology (Vyshcha Shkola, 1989) (in Russian).

14. V.D. Romanenko, Yu. G. Krot, L.A. Syrenko, V.D. Solomatina. Biotechnology of Hydrobionts Cultivation (Inst. of Hydrobiology, Kyiv, 1999) (in Russian).

15. U. Kogelschatz. Fundamentals and Applications of Dielectric-barrier Discharges (ABB Corparate Research Ltd, 5405 Dfden, 2000).

16. T.E. Kuleshova, A.I. Likhachev, E.S. Pavlova et al. Interrelation between absorption spectra of plant pigments and LED illumination with various spectral compositions. $Z h$. Tekhn. Fiz. 88, 1285 (2018) (in Russian).

17. G.B. Popovych, A.O. Malinina, I.I. Aksenyuk, R.V. Grytsak. Influence of additional artificial illumination on the initial growth and development stages of tomato and cucumber seedlings. Ovochiv. Bashtann. 64, 44 (2018) (in Ukrainian).

18. G. Zissis, S. Kitsinelis. State of art on the science and technology of electrical light sources: from the past to the future. J. Phys. D 42, 173001 (2009).

19. U. Kogelschatz. Ultraviolet excimer radiation from nonequilibrium gas discharges and its application in photophysics, photochemistry and photobiology. J. Opt. Technol. 79, 484 (2012)

20. A.A. Malinina, A.K. Shuaibov, A.N. Malinin. Optical emission of atmospheric-pressure dielectric barrier discharge plasma on mercury diiodide/rare gases mixtures. IOSR J. Appl. Phys. 9, 51 (2017).

21. V.B. Basov. LEDs: advantages and disadvantages. ElektroZh. 6, 34 (2010) (in Russian).

22. Properties of Inorganic Compounds. A Handbook. Edited by A.I. Efimov, L.P. Belorukova, I.V. Vasilkova, V.P. Chechev (Khimiya, 1983) (in Russian).

23. R.A. Sapozhnikov. Theoretical Photometry (Energiya, 1977) (in Russian).

24. R.W. Pears, A.G. Gaydon. The Identification of Molecular Spectra (Chapman and Hall, 1963).

25. Yu.S. Akishev, A.V. Dem'yanov, V.B. Karalnik et al. Pulsed regime of the diffusive mode of a barrier discharge in helium Fiz. Plazmy 27, 176 (2001) (in Russian).

26. G.J.M. Hagelaar, L.C. Pitchford. Solving the Boltzmann equation to obtain electron transport coefficients and rate coefficients for fluid models. Plasma Sourc. Sci Technol. 14, 722 (2005).

27. https://www.bolsig.laplace.univ-tlse.fr/.

28. V. Kushawaha, M.J. Mahmood. Electron impact dissociation of $\mathrm{HgX}_{2}(\mathrm{X}=\mathrm{Cl}, \mathrm{Br}, \mathrm{I})$. Appl. Phys. 62, 2173 (1987).

29. A.N. Malinin. Excitation of the $B^{2} \Sigma_{1 / 2}^{+}$state of mercury monohalides by electron impact. Laser Phys. 7, 1177 (1997).

30. Yu.P. Raizer, Gas Discharge Physics (Springer, 1997).

31. A. Mandl, J.J. Parks, C. Roxlo. Collisional quenching kinetics for the $\mathrm{HgCl}^{*}$ and $\mathrm{HgBr}^{*}\left(B^{2} \Sigma_{1 / 2}^{+}\right)$state. J. Chem. Phys. 72, 504 (1980).

32. A.N. Malinin. The efficiency of the quenching of the $B^{2} \Sigma_{1 / 2}^{+}$state in mercury monohalides by halogencontaining molecules in active media of $\mathrm{HgCl}, \mathrm{HgBr}$, and HgJ excimer lasers. Laser Phys. 7, 1177 (1997).

33. W.R. Wadt. The electronic structure of $\mathrm{HgCl}_{2}$ and $\mathrm{HgBr}_{2}$ and its relationship to photodissociation. J. Chem. Phys. 72, 2469 (1980).

34. W.L. Nighan, R.T. Brown. Kinetic processes in the $\operatorname{HgBr}(B \rightarrow X) / \mathrm{HgBr}_{2}$ dissociation laser. J. Appl. Phys. 53, 7201 (1982).

35. W.R. Wadt. The electronic structure of $\mathrm{HgCl}$ and $\mathrm{HgBr}$. Appl. Phys. Lett. 34, 658 (1979).

36. V.V. Datsyuk, I.A. Izmailov, V.A. Kochelap. Vibrational relaxation of excimer molecules. Usp. Fiz. Nauk 168, 439 (1998) (in Russian).

37. Applied Atomic Collision Physics. Vol. 3: Gas Lasers. Edited by E.W. McDaniel, W.L. Nighan (Academic Press, New York, 1982).

38. V.V. Datsyuk, I.A. Izmailov, V.V. Naumov, V.A. Kochelap. Direct electron-impact mechanism of excitation of mercury monobromide in a double-pulse dielectric-barrierdischarge $\mathrm{HgBr}$ lamp. Plasma Sourc. Sci. Technol. 25, 045020 (2016).

39. A.C. Erlandson, T.A. Cool. On the regeneration mechanism of $\mathrm{HgBr} / 2$ in $\mathrm{HgBr} / \mathrm{HgBr}_{2}$ dissociation lasers. Chem. Phys. Lett. 96, 685 (1983).

Received 04.04.19.

Translated from Ukrainian by O.I. Voitenko ISSN 2071-0194. Ukr. J. Phys. 2019. Vol. 64, No. 9 
А.О. Малініна, О.К. Шуаібов, О.М. Малінін МЕХАНІЗМ ЗБІЛЬШЕННЯ ПОТУЖНОСТІ ВИПРОМІНЮВАННЯ ГАЗОРОЗРЯДНОЇ ЛАМПИ НА СУМІШАХ ПАРІВ ДИХЛОРИДУ РТУТІ, НЕОНУ ТА АЗОТУ В СИНЬО-ЗЕЛЕНОМУ СПЕКТРАЛЬНОМУ ДІАПАЗОНІ

$\mathrm{P}$ е $з$ ю м е

Встановлено механізм збільшення потужності випромінювання газорозрядної лампи на сумішах парів дихлориду ртуті, азоту та неону в порівнянні з сумішшю парів дихлориду ртуті і неону в синьо-зеленому спектральному діапазоні. Встановлено оптичні характеристики, параметри плазми, величину приведеного електричного поля, при якому питома потужність розряду, що вноситься в збудження ексиплексних молекул монохлориду ртуті, максимальна. Результати досліджень можуть бути використані для створення більш ефективної ексиплексної лампи, що випромінює спектральні смуги в синьо-зеленому спектральному діапазоні. 